\title{
L'anévrisme de l'aorte abdominale, une maladie fréquente mais mal connue
}

La rupture d'un anévrisme de l'aorte abdominale représente la cause de mort de 1,3\% environ des hommes âgés de plus de 50 ans. La taille de l'anévrisme détermine le risque de rupture: si le diamètre de l'anévrisme est supérieur ou égal à $5 \mathrm{~cm}$, ce risque est de $25 \%$ en 5 ans selon une étude récente faite à la Mayo Clinic [1] ; ce risque est inférieur à celui estimé dans des études plus anciennes. L'intervention chirurgicale est grevée d'une mortalité de 85 à $95 \%$ en cas d'anévrisme rompu; en revanche la mortalité n'est que de $2 \%$ environ, si l'anévrisme est opéré "à froid ", en dehors de toute complication.

Ces données épidémiologiques expliquent l'intérêt porté aux anévrismes aortiques et aux facteurs qui en déterminent la formation. Beaucoup de ces anévrismes sont familiaux (voir $\mathrm{m} / \mathrm{s} n^{\circ} 4$, vol. 6, p. 403), $15 \%$ des malades opérés ont un parent également atteint. Kontusaari et al. [2], à Philadelphie, ont identifié une famille où 4 sujets avaient un anévrisme aortique. Les membres de cette famille n'avaient pas de syndrome d'EhlersDanlos type IV ou de syndrome de Marfan, syndromes où coexistent des anévrismes artériels et d'autres anomalies systémiques. Certaines manifestations cliniques, cependant, pouvaient faire évoquer l'un ou l'autre de ces syndromes. Chez une femme hétérozygote de 37 ans, indemne d'anévrisme, a été mise en évidence une mutation ponctuelle qui transforme le codon pour la glycine 619 de la chaîne $\alpha_{1}$ du procollagène de type IV en un codon pour l'arginine. Le collagène de type IV est un homotrimère constitué de 3 chaî- nes $\alpha_{1}$ synthétisées à partir d'un seul gène (COL3A1). Des mutations touchant ce gène ont été identifiées dans le syndrome d'Ehlers-Danlos type IV.

La même mutation a été retrouvée chez deux malades de cette famille décédés de rupture d'anévrisme, à partir de l'étude de fragments d'aorte abdominale qui avaient été prélevés chirurgicalement. De même la mutation a été mise en évidence à partir de l'étude de l'ADN salivaire chez d'autres membres apparemment asymptomatiques de la même famille. La mutation s'accompagne d'une anomalie fonctionnelle du fragment du procollagène de type IV contenant l'acide aminé substitué en position 619: le procollagène témoin résiste à une digestion protéasique jusqu'à $36^{\circ} \mathrm{C}$ environ ; au contraire, le procollagène provenant des fibroblastes en culture du propositus est " clivé " à partir de $20^{\circ} \mathrm{C}$ et le fragment obtenu est d'environ 620 acides aminés.

L'approche choisie par Anidjar et al. [3] (Inserm U. 36-7 et U. 28, hôpital Broussais et hôpital SaintMichel) est toute différente. Ces auteurs ont induit un anévrisme de l'aorte chez le rat en perfusant in vivo un segment isolé de l'aorte abdominale par une solution contenant de l'élastase pancréatique. En effet, l'anévrisme chez l'homme s'accompagne d'une perte du tissu élastique et d'une activité élastolytique accrue dans la média artérielle. Chez le rat, la formation de l'anévrisme dépend de la dose d'élastase perfusée. D'autres protéases induisent des anévrismes plus petits mais elles altèrent également le tissu élastique. L'admi- nistration conjointe de plasmine accroît les effets de l'élastase (ainsi que ceux de macrophages activés, produisant diverses protéases dont l'élastase). Il faut rappeler que l'anévrisme de l'aorte abdominale contient souvent chez l'homme des thrombus ; l'activité fibrinolytique (qui passe par la plasmine) est augmentée et la production accrue de plasmine pourrait amplifier l'activité élastolytique.

A partir de deux voies d'approche différentes, ces deux études suggèrent deux mécanismes physiopathologiques différents à l'origine des anévrismes aortiques. Des facteurs génétiques pourraient être impliqués dans les deux cas : Andijar et al [3] indiquent que la souris "Blotchy " développe des anévrismes aortiques, du fait d'une mutation localisée sur le chromosome $\mathrm{X}$, créant un défaut d'absorption intestinale du cuivre. Il en résulte une dysfonction de la lysyloxydase, une enzyme impliquée dans l'arrangement des fibrilles d'élastine et de collagène. Cette souche de souris développe un anévrisme dans $100 \%$ des cas à 6 mois ; elle présente également un emphysème pulmonaire du fait de la lyse progressive des septa alvéolaires pulmonaires.

J.-P.G.

1. Nevitt MP, Ballard DJ, Hallett JW JR. Prognosis of abdominal aortic aneuryms. $N$ Engl J Med 1989 ; 321 : 1009.14.

2. Kontusaari S, Tromp G, Kuivaniemi II, el al. A mutation in the gene for type III procollagen (COL3A1) in a family with aortic aneurysms. J Clin Invest 1990 ; 86 : 1465-73. 3. Anidjar S, Salzmann JL, Gentrie D, el al. Elastase-induced experimental aneurysms in rats. Circulation $1990 ; 82: 673-81$. 